\section{Crystallization and nucleation study of transition metal phosphates: M- struvite and related compounds}

\author{
STEPHANOS KARAFILUDIS ${ }^{1}$ AND TOMASZ MACIEJ \\ STAWSKI $^{2}$ \\ ${ }^{1}$ Federal Institute for materials research and testing \\ ${ }^{2}$ Federal Institute for Materials Research and Testing (BAM) \\ Presenting Author: stephanos.karafiludis@bam.de
}

The recycling of critical elements has crucial importance to maintain sustainable use of raw materials. Phosphorus(P) is a sought-after limited natural resource due to its wide use in modern agriculture mainly as P-fertilizers. But it causes also major problems for the environment such as eutrophication of ecosystems. In the future it could be depleted due to the high demand and rapidly declining natural phosphorite ore deposits. Therefore, the phosphorus recovery from agricultural waste waters will be an important factor in preservation of the global consumption. The precipitation of $\mathrm{M}$-struvite $\left(\mathrm{NH}_{4} \mathrm{MPO}_{4} \cdot 6 \mathrm{H}_{2} \mathrm{O}\right.$, $\mathrm{M}^{2+}=\mathrm{Ni}^{2+}, \mathrm{Co}^{2+}, \mathrm{Mn}^{2+}$ ) from waste waters is a promising $\mathrm{P}-$ recovery route. Besides avoidance of eutrophication due to extraction of excess phosphates and the restoration of the phosphorus resources the recovered M-struvites may be potentially be up-cycled for industrial applications e.g. Co and Ni-phosphate show excellent electrochemical properties for batteries or supercapacitors.

The precipitation processes of M-struvites are strongly dependent on the degree of supersaturation, $\mathrm{pH}$ and on the exchange ions $\mathrm{M}^{2+}$. The impact of transition metals on the crystallization of M-struvite has been investigated only to a limited extent. An optimization of the reaction conditions could lead to more efficient M-struvite precipitation and significantly improved P-recovery method. We considered different cations based on their ionic radii and performance in electrocatalysis. Here, we prove that Ni-struvite is stable at different concentration of nickel and phosphate/ammonia in contrast to Co-struvite which forms only at lower concentration of $\mathrm{Co}^{2+}$. The M-struvite crystals exhibit a strong dependency of their shape and size on the concentration of phosphate/ammonia and $\mathrm{M}^{2+}$ (Figure 1). In order to validate the coordination environment, EXAFS measurements were performed (Figure 2). All metal cations occur as bivalent ions $\mathrm{M}^{2+}$ and are octahedrally coordinated by six oxygen atoms. Ni struvite demonstrates a nearly ideal $\mathrm{NiO}_{6}$ octahedron while Co-struvite exhibits a strongly distorted $\mathrm{CoO}_{6}$ octahedron.

Figure 1: $\mathrm{c}(\mathrm{Ni} 2+)$ vs. $\mathrm{c}(\mathrm{DAP}) \quad[\mathrm{DAP}=$ Diammonium hydrogen phosphate $\left.\left(\mathrm{NH}_{4}\right)_{2} \mathrm{HPO}_{4}\right]$ diagram

Figure 2: XAS spectrum of $\mathrm{Ni}$ and $\mathrm{Co}$ (left) and the fitted EXAFS plot for Ni- and Co-struvite in real R-space; $\mathrm{R}(\mathrm{Ni})=$ $0.005, \mathrm{R}(\mathrm{Co})=0.009$ (right)
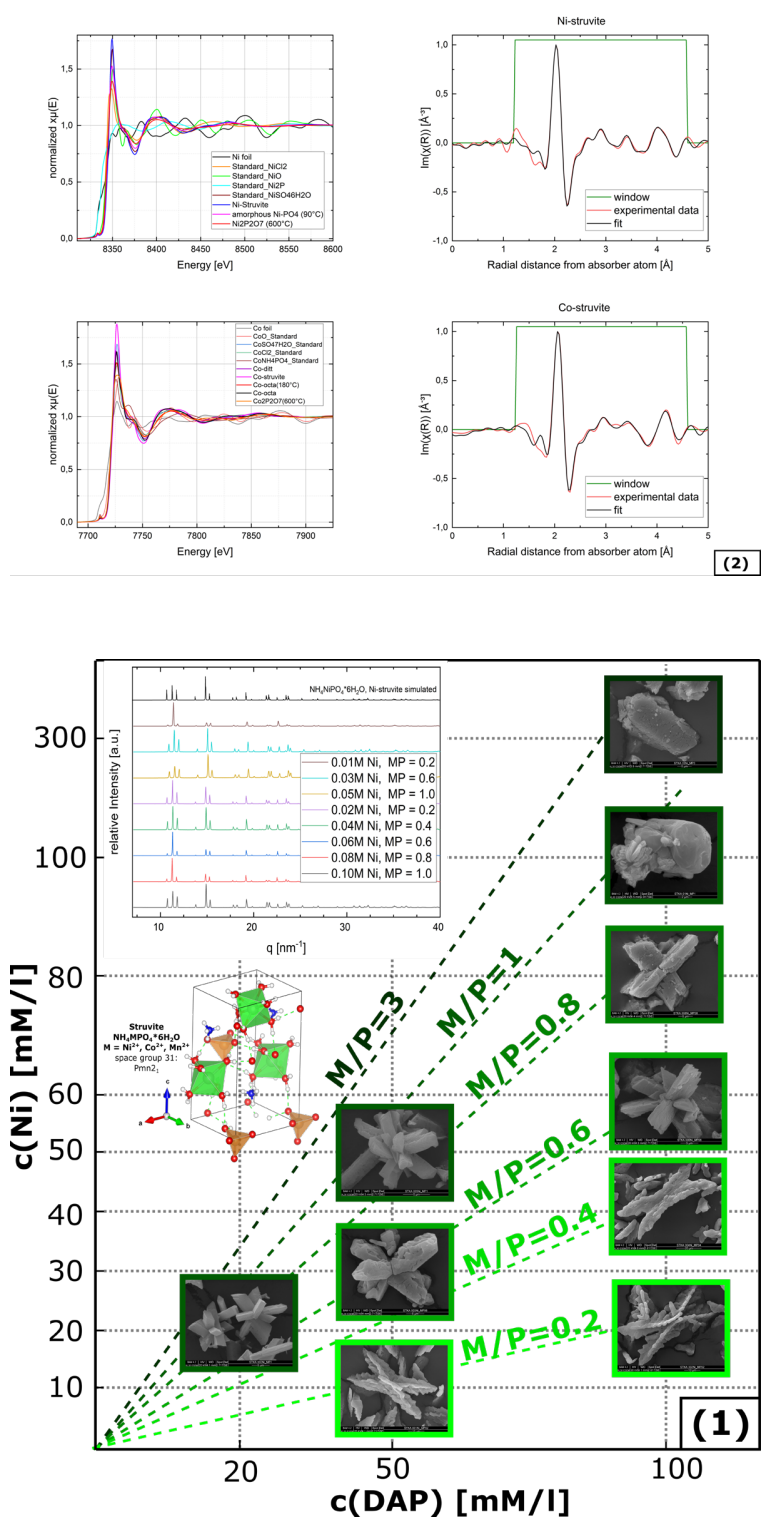